\title{
The influence of metahalloysite addition on tobermorite formation studied by X-ray powder diffraction and scanning electron microscope
}

\author{
Anna Skawińska ${ }^{1, *}$ \\ ${ }^{1}$ Institute of Ceramics and Building Materials, Division of Glass and Building Materials in Cracow, \\ Cementowa Str. 8, Cracow 31-983, Poland
}

\begin{abstract}
This paper presents the results of the studies carried out in the model systems and concerning the tobermorite synthesis with an addition of metahalloysite. Quartz sand and quicklime were the main raw material constituents. The mixtures in the form of slurries underwent hydrothermal treatment with an addition of metahalloysite $(5 \%, 10 \%, 15 \%, 20 \%$ and $30 \%)$ for 4 hours and 12 hours. The resultant composites were analysed for their phase composition using X-ray powder diffraction. The microstructure was examined using the Scanning Electron Microscope. Tobermorite was the principle reaction product. When $30 \%$ metahalloysite was added to the mixture containing $\mathrm{CaO}$ and $\mathrm{SiO}_{2}$, the formation of katoite was found.
\end{abstract}

\section{Introduction}

Tobermorite is the principal phase formed in autoclaved building composites, the one which provides the final products with appropriate mechanical properties. Until now three tobermorite phases have been distinguished on the basis of their basal spacing: $14 \AA$ tobermorite- $\mathrm{Ca}_{5} \mathrm{Si}_{6} \mathrm{O}_{16}(\mathrm{OH})_{2} \cdot 7 \mathrm{H}_{2} \mathrm{O}, 11 \AA$ tobermorite- $\mathrm{Ca}_{5} \mathrm{Si}_{6} \mathrm{O}_{16}(\mathrm{OH})_{2} \cdot 5 \mathrm{H}_{2} \mathrm{O}$ and water free $9 \AA$ tobermorite $\mathrm{Ca}_{5} \mathrm{Si}_{6} \mathrm{O}_{16}(\mathrm{OH})_{2}$. The most important type is $11 \AA$ tobermorite, which is the major phase found in aerated autoclaved concretes. Understanding the mechanism of tobermorite formation in the autoclave process is very important for the production of AAC [1-5]. Huston et al. [6] stated, that tobermorite formation proceeds in three stages: formation of amorphous C-S-H phase, increase in semi-crystalline tobermorite content and its crystallization. Numerous studies shown, that reactive silica, aluminium, $\mathrm{Na}$ and $\mathrm{K}$ or sulphates compounds have significant influence on tobermorite synthesis [6-9].

The tobermorite was synthesized with an addition of metahalloysite. Metahalloysite was obtained by dehydroxylation of halloysite [10-11]. This reaction can be presented as the schematic formula

$$
\mathrm{Al}_{2} \mathrm{Si}_{2} \mathrm{O}_{5}(\mathrm{OH})_{4} \rightarrow \mathrm{Al}_{2} \mathrm{Si}_{2} \mathrm{O}_{7}+2 \mathrm{H}_{2} \mathrm{O}
$$

Since tobermorite is important phase of autoclaved building composites, the influence of metahalloysite addition and autoclaving time on this phase formation in constant autoclaving

\footnotetext{
* Corresponding author: a.skawinska@icimb.pl
} 
conditions corresponding to saturated water vapour pressure at temperature of $180^{\circ} \mathrm{C}$ were examined.

\section{Materials, methods and samples preparation}

Raw materials used to obtain autoclaved composites included silica sand and quicklime. The silica sand chosen met the PN-EN 196-1 criteria. Grains with the size less than $0.5 \mathrm{~mm}$ were ground to reach the Blain fineness of $6560 \mathrm{~cm}^{2} / \mathrm{g}$. The quicklime was obtained by subjecting pure calcium carbonate to the heat of $1000^{\circ} \mathrm{C}$ for $2 \mathrm{~h}$. Natural halloysite, used to obtain the metahalloysite, came from the Dunino mine, near Legnica. Metahalloysite was obtained by thermal treatment of halloysite at the temperature of $750^{\circ} \mathrm{C}$ for 2 hours. This mineral was used as an admixture $5 \%, 10 \%, 15 \%, 20 \%$ and $30 \%$ by weight of the joint weight of $\mathrm{CaO}$ and $\mathrm{SiO}_{2}$.

Tobermorite was synthesized at the $\mathrm{CaO} / \mathrm{SiO}_{2}$ molar ratio of 0.86 . The ratio of water $w$ to the amount of solid constituents $s$ was $2(\mathrm{~W} / \mathrm{S}=2)$. The constituents were placed in plastic containers and homogenized for 5 minutes. Metahalloysite was added towards the end of mixing the main components. The slurries were then poured into PTFE moulds and moved into a laboratory autoclave and held at $180^{\circ} \mathrm{C}$ for 4 and 12 hours at a saturated steam atmosphere. The temperature in the autoclave was elevated with the rate of $1.5 \% \mathrm{~min}$. The specimens were dried under vacuum to prevent them from being contaminated with $\mathrm{CO}_{2}$.

The phase composition and the microstructure of the composites was examined using an X-ray diffraction method (EMPYREAN manufactured by PANalytical) and scanning electron microscope (Quanta 250 FEG manufactured by ThermoFisher Scientific) in the low vacuum mode. The steam atmosphere was $30 \mathrm{~Pa}$. The microstructure of halloysite and metahalloysite are shown in Fig.1a and Fig.1b respectively. Details of raw material composition are given in Table 1.

a)

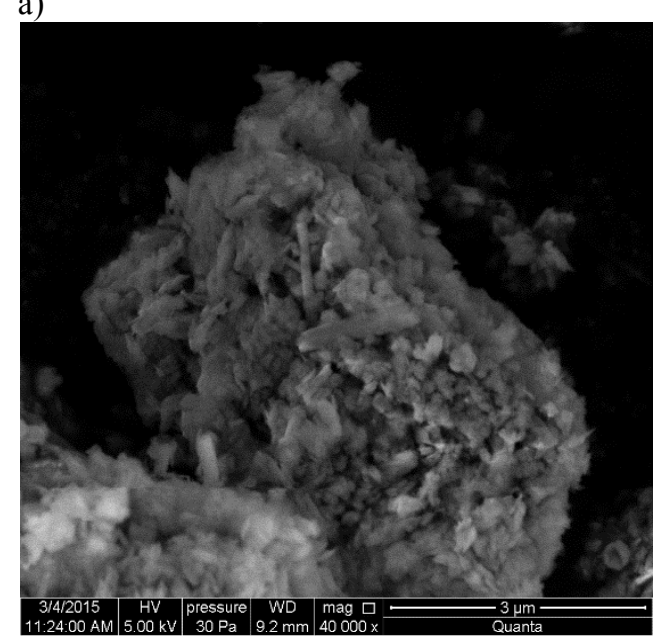

b)

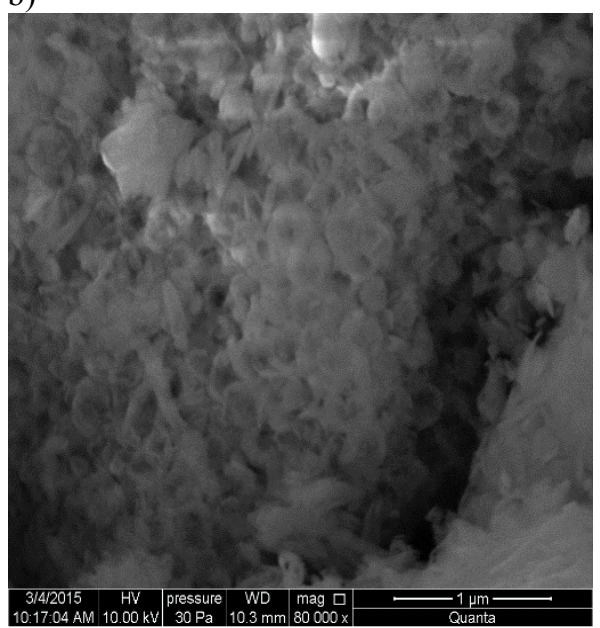

Fig. 1. The microstructure of a) halloysite b) metahalloysite.

Halloysite is consist of irregular forms and spatially dispersed tubes. Metahalloysite is amorphous and the particles with tubular morphology, typical for halloysie, are not found. 
Table 1. Chemical composition of raw materials as determined by X-ray fluorescence.

\begin{tabular}{|c|c|c|c|}
\hline Oxide [\%] & Quicklime & Quartz & Metahalloysite \\
\hline $\mathrm{SiO}_{2}$ & $\mathrm{NS}^{*}$ & 99.6 & 49.6 \\
\hline $\mathrm{K}_{2} \mathrm{O}$ & $\mathrm{NS}^{*}$ & $\mathrm{NS}^{*}$ & 0.1 \\
\hline $\mathrm{TiO}_{2}$ & $\mathrm{NS}^{*}$ & $\mathrm{NS}^{*}$ & 2.0 \\
\hline $\mathrm{Al}_{2} \mathrm{O}_{3}$ & $\mathrm{NS}^{*}$ & $\mathrm{NS}^{*}$ & 41.5 \\
\hline $\mathrm{Fe}_{2} \mathrm{O}_{3}$ & $\mathrm{NS}^{*}$ & $\mathrm{NS}^{*}$ & 5.7 \\
\hline $\mathrm{P}_{2} \mathrm{O}_{5}$ & $\mathrm{NS}^{*}$ & $\mathrm{NS}^{*}$ & 0.8 \\
\hline $\mathrm{CaO}$ & 99.8 & $\mathrm{NS}^{*}$ & 0.3 \\
\hline
\end{tabular}

$\mathrm{NS}^{*}$ - not studied

\section{Results}

Sample designations and metahalloysite percentage share in mixes composed of quicklime and silica are given in Table 2 .

Table 2. Designation of autoclaved mixes with metahalloysite.

\begin{tabular}{|c|c|c|c|c|c|c|}
\hline Designation of samples & A1 & MA1 & MA2 & MA3 & MA4 & MA5 \\
\hline Metahalloysite content [\%] & 0 & 5 & 10 & 15 & 20 & 30 \\
\hline
\end{tabular}

Phase compositions of mixes composed of quartz sand and $\mathrm{CaO}$ with metahalloysite after $4 \mathrm{~h}$ and $12 \mathrm{~h}$ of autoclaving process are presented on Figs. 2-3.

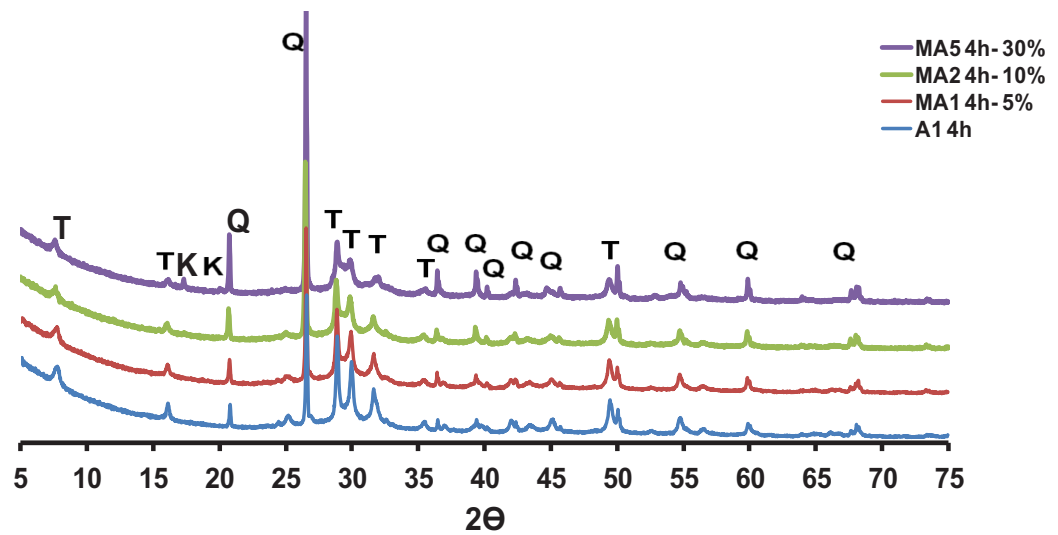

Fig. 2. X-ray diffraction patterns of mixes with metahalloysite addition, autoclaving time 4 hours. Ttobermorite, K- katoite, Q- quartz. 


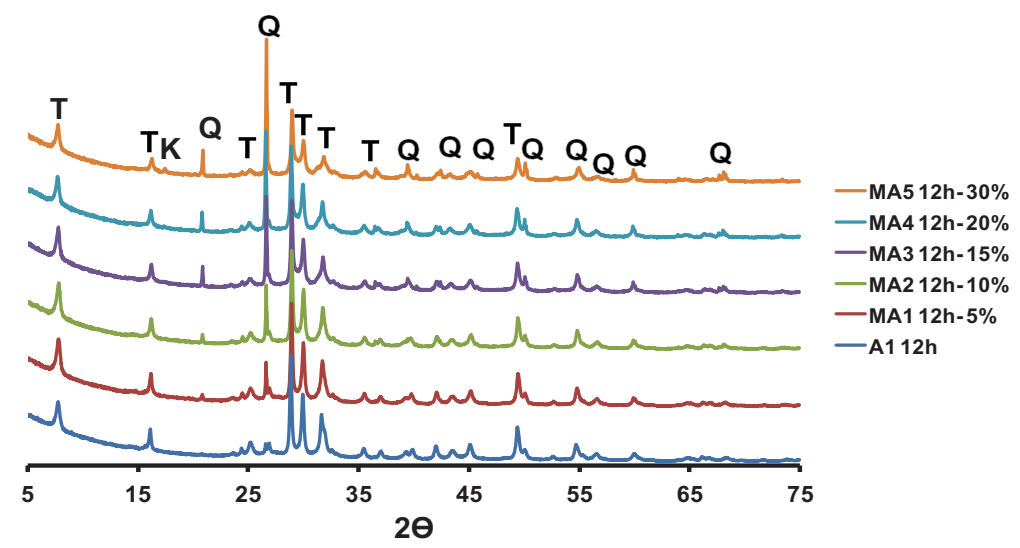

Fig. 3. X-ray diffraction patterns of mixes with metahalloysite addition, autoclaving time 12 hours. Ttobermorite, K- katoite, Q- quartz.

$\mathrm{X}$-ray pattern analysis (Figs. 2,3) shown that primary synthesis product in samples with methalloysite is tobermorite. Except this phase, quartz is also present, but the intensity of this phase decreased with reaction time (after 12 hours). Katoite occurs in samples with $30 \%$ of metahalloysite after 4 hours. This phase appears when $\mathrm{Al} /(\mathrm{Al}+\mathrm{Si})$ molar ratio exceeds 0.15 . Hydrogarnet did not disappear after 12 hours. According to Klimesh et al. [12-16], katoite is indirect phase in tobermorite formation. Hydrogarnets durability decreases with increase in silica content and the extension of autoclaving time. Metahalloysite was not present in any sample. It means that this mineral completely reacted, and $\mathrm{SiO}_{2}$ contained in metahalloysite is more reactive than quartz sand, therefore it quickly reacts with calcium ions.

Microscopic examinations confirmed the phase composition results from the XRD analysis. Figs. 4-5 show SEM selected images of the morphology of calcium silicate hydrates $(\mathrm{C} / \mathrm{S}=0.86)$ with metahalloysite. Observations under scanning electron microscope have shown, that time of synthesis and presence of mineral additions influence on products morphology. After 4 hours of autoclaving process, poorly crystallized calcium silicate hydrates are observed. Well-developed concentrations of tobermorite were observed in the samples without metahalloysite after 12 hours. In the sample containing 30\% of metahalloysite, tobermorite is accompanied by hydrogarnets. The typical octahedral morphology of hydrogarnet occurring in twinned crystals is illustrated in Fig.5. Tobermorite occurs in the form of flattened laths. 
a)

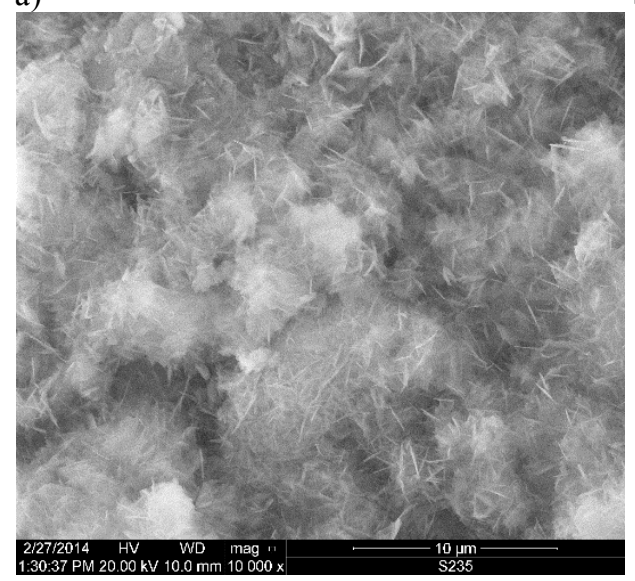

b)

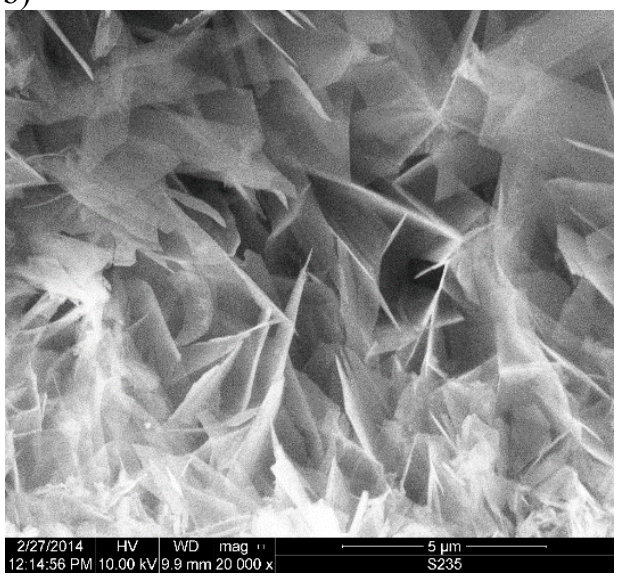

Fig. 4. Microstructure of reference sample after a) 4 hours b) 12 hours.
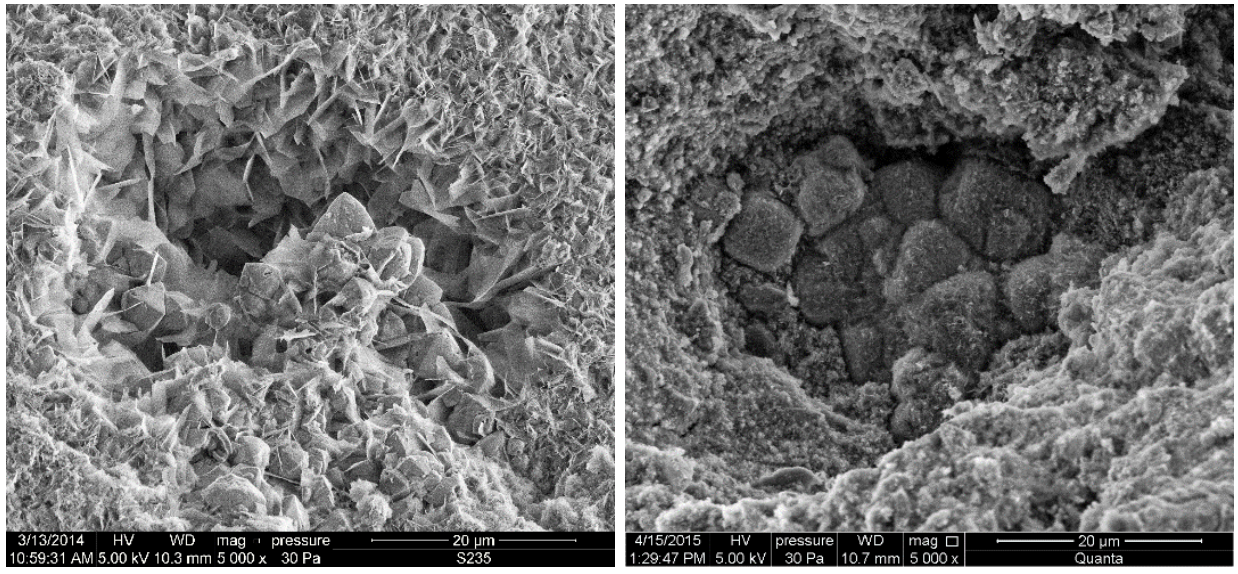

Fig. 5. Microstructure of sample with $30 \%$ of metahalloysite addition.

\section{Analysis of the results}

Tobermorite under hydothermal conditions can be synthesized with an addition of clay mineral such as metahalloysiye. Test results of samples with metahalloysite addition shown, that variable phase composition is obtained depending on the amount of used metahalloysite. Only tobermorite and quartz are observed in samples with metahalloysite addition in amount to $20 \%$. Metahalloysite addition higher than $20 \%$ caused, except tobermorite, also katoite formation. Microstructure analysis under scanning electron microscope shown, that extension of hydrothermal treatment time favours the formation of calcium silicate hydrates with ordered structure. Hydrogarnets crystals in the form of rhombic octahedron were present in samples with $30 \%$ of metahalloysite addition.

\section{References}

1. S.A.S. El-Hemaly, T. Mitsuda, H.F.W. Taylor, Cem. Concr. Res. 7, 429 (1977)

2. H.F.W. Taylor, The Chemistry of Cements, Academic Press (London, 1964) 
3. K. Luke, H.F.W. Taylor, G.L. Kalousek, Cem. Concr. Res. 11(2), 197-203 (1981)

4. H.F.W. Taylor, Proc.4th Intern. Symp.Chem.Cem., 176-232 (Washington, DC, 1960)

5. H.F.W. Taylor, J.Am.Chem. Soc., 163-167 (1953)

6. J.H. Huston, R.S. Maxwell, S.A. Caroll, Geochem.Trans. 10, 510-519 (2009)

7. A.J. Hamad, Inter. J.Mat. Sci.Eng. 2(2), 152-157 (2014)

8. K. Matsui, J. Kikuma, M. Tsunashima, T. Ishikawa, S. Matsuno, A. Ogawa, M. Sato, Cem.Con. Res. 41, 510-519 (2011)

9. E.V. Fomina, V.V. Strokova, World Applied Science Journal 25(1), 48-54 (2013)

10. L. Stoch, Mineraty ilaste, (Wydawnictwa Geologiczne, Warsaw, 1974 in Polish)

11. S. Guggenheim et al., Clays and Clay Minerals 54, 761 (2006)

12. D.S. Klimesh, A. Ray, Cem. Con. Res. 28(9), 1309-1316 (1998)

13. D.S. Klimesh, A. Ray, Cem.Con. Res. 28(9), 317-1323 (1998)

14. D.S. Klimesh, A. Ray, Cem.Con. Res. 28(8), 1109-1117 (1998)

15. D.S. Klimesh, A. Ray, Thermochimica Acta 334, 115-122 (1999)

16. D.S. Klimesh, A. Ray, J.Thermal Analysis and Calorimetry 56, 27-34 (1999) 